\title{
A conformação das cidades novas planejadas no Brasil do
} século vinte

The configuration of the new towns planned in twentieth-century Brazil

La conformación de las nuevas ciudades creadas en el Brasil del siglo veinte

REGO, Renato Leão ${ }^{1}$

1Programa Associado de Pós-Graduação em Arquitetura e Urbanismo UEM-UEL, Departamento de Arquitetura e Urbanismo, Universidade Estadual de Maringá, Londrina, Brasil. rlrego@uem.br ORCID ID: 0000-0003-1822-2907 


\title{
Resumo
}

Este artigo analisa as cidades criadas nas frentes pioneiras de colonização agrícola no Brasil do século XX. Como múltiplo estudo de caso, em perspectiva comparativa, são analisados os empreendimentos privados de colonização do norte do Paraná e do norte do Mato Grosso, além da iniciativa estatal na Amazônia, que criaram conjuntos de novas cidades no período entre os anos 1930 e 1970. Apoiada em extensa bibliografia, a análise considera a concretização de ideias urbanísticas em circulação global, as formas urbanas produzidas e seu contexto cultural. Como resultado o trabalho reconhece a transformação física do território atrelada à noção de desenvolvimento das políticas governamentais vigentes; o trabalho remoto dos projetistas das novas cidades como produto de experiências metropolitanas; a adaptação seletiva, a transformação e o hibridismo das ideias urbanísticas incorporadas; o planejamento regional tributário do ideário cidade jardim, com estrutura urbana hierarquizada e configuração de regiões urbanas; a arte urbana como preceito para os projetos desenvolvidos majoritariamente por engenheiros na primeira metade do século em contrapartida à hegemonia da cidade funcional dos arquitetos no período posterior; e, por fim, a prevalência da grelha como padrão de traçado urbano.

Palavras-Chave: circulação de ideias; urbanismo transnacional; cidades novas; cidade jardim; desenho urbano; planejamento regional

\begin{abstract}
This paper analyzes new towns created in twentieth-century Brazilian pioneering agricultural frontiers. Private colonization enterprises in northern Paraná state and northern Mato Grosso state as well as the federal settlement project in Amazonia, which created groups of new towns in the period ranging from 1930s to 1970s, are analyzed as a multiple case study, drawn on comparative perspective. Supported by vast bibliography, the analysis considers the local materialization of urban ideas in global diffusion, ensuing urban forms and their cultural context. As a result, the paper states the physical transformation of the territory as part of the development notion depicted in governmental policies; new town planners' remote work as a product of metropolitan experiences; selective-adaptation, transformation and hybridization of related planning ideas; regional planning stemmed from the garden city ideal, regarding hierarchical urban structure and the configuration of urban regions; urban art as the design orientation for layouts prepared by engineers in the first half of the century in contrast to the hegemonic functional city produced by architects in the following half-century; and, lastly, the grid as the prevalent urban layout pattern.
\end{abstract}

Key-Words: planning diffusion; transnational planning; new towns; garden city; urban design; regional planning

\section{Resumen}

Este artículo analiza nuevas ciudades creadas en las frentes pioneras de colonización agrícola en el Brasil del siglo veinte. Como un múltiplo estudio de caso, en perspectiva comparativa, son analizados los emprendimientos privados de colonización en el norte del estado de Paraná y del estado de Mato Grosso, así como la iniciativa estatal en Amazonia, que crearon conjuntos de nuevas ciudades entre los años 1930 y 1970. Apoyado en extensa bibliografía, el análisis considera la materialización local de ideas urbanísticas en circulación global, las formas urbanas producidas y su contexto cultural. Como resultado, el trabajo reconoce la transformación física del territorio como parte de la noción de desarrollo en las políticas gubernamentales vigentes; el trabajo remoto de los proyectistas como producto de experiencias metropolitanas; la adaptación selectiva, la transformación y el hibridismo de las ideas urbanísticas incorporadas; la planificación regional como tributaria del ideario ciudad jardín, con estructura urbana jerarquizada y configuración de regiones urbana; el arte urbano como precepto para los proyectos mayoritariamente desarrollados por ingenieros en la primera mitad del siglo en contraste con la hegemónica ciudad funcional de los arquitectos en el período posterior; y, por fin, la prevalencia de la grilla como padrón del trazado urbano.

Palabras clave: circulación de ideas; urbanismo transnacional; ciudades nuevas; ciudad jardín; diseño urbano; planificación regional 


\section{Introdução}

Estudos que exploraram a repercussão de ideias urbanísticas transnacionais no Brasil do século $X X$ não deixaram de aludir à criação de cidades planejadas no país (LEME, 2005; LEME, 2004; ANDRADE, 2010; ANGOTTI-SALGUEIRO e SIMÕES JUNIOR, 2017; SEGAWA, 1997; REGO, 2019). Esses estudos, reunidos e postos em perspectiva, induzem à reflexão ampla, de cunho comparativo, que desencadeia este artigo. Esta reflexão se depara, de imediato, com a questão principal que se trata de responder aqui: como foram conformadas as cidades criadas no Brasil do século XX?

A criação de novas cidades capitais, certamente pela singularidade no caráter e na grandeza do empreendimento, acumula bibliografia mais extensa (VIDAL, 2009; TAVARES, 2014; BRAGA, 2010; BRAGA, 2011; MANSO, 2001; XAVIER e KATINSKY, 2012; REIS, 2015; REGO, 2020; TREVISAN, FICHER e MATTOS, 2017). Menos exploradas, as cidades interioranas de menor porte - em maior número e menos conhecidas - foram responsáveis pela transformação que fez do Brasil um país majoritariamente urbano, em meados dos anos 1960 (TREVISAN, 2009; REGO, 2019). Em grande medida, estas novas cidades espalhadas no interior agrícola do país foram campos de experimentos para ideias urbanísticas pioneiras. Logo, este artigo observa as cidades criadas junto às frentes de colonização agrícola, privadas e estatais. Isto quer dizer que este artigo abrange, progressivamente, os estados do Paraná, do Mato Grosso, do Mato Grosso do Sul e a Bacia Amazônica, acompanhando o movimento de desbravamento do interior do país ao longo do século XX. A colonização do norte do Paraná iniciada no final dos anos 1920 decorreu do avanço da cafeicultura pelo interior do estado de São Paulo, como mostrou Monbeig (1984), e rumou em direção ao oeste paranaense; em meados do século passado a frente pioneira de colonização continuou progressivamente pelo centro-oeste, atingindo a Bacia Amazônica nos anos 1970. Em meio a núcleos de colonização avulsos e menos conectados, pode-se notar ali que o povoamento foi linear, já que a frente pioneira de colonização seguiu o traçado previsto para a ferrovia no caso paranaense e nos estados da Bacia Amazônica acompanhou as novas rodovias, mas, diferentemente do que entendeu Waibel (1955), nestes casos o esquema planejado contava com conexão na retaguarda.

Figura 1: Imagem aérea de Sinop-MT, projeto de 1972 da Colonizadora SINOP a partir de diretriz do INCRA, revisado e ampliado pelo arquiteto Alfredo Clodoaldo de Oliveira Neto em 1979.

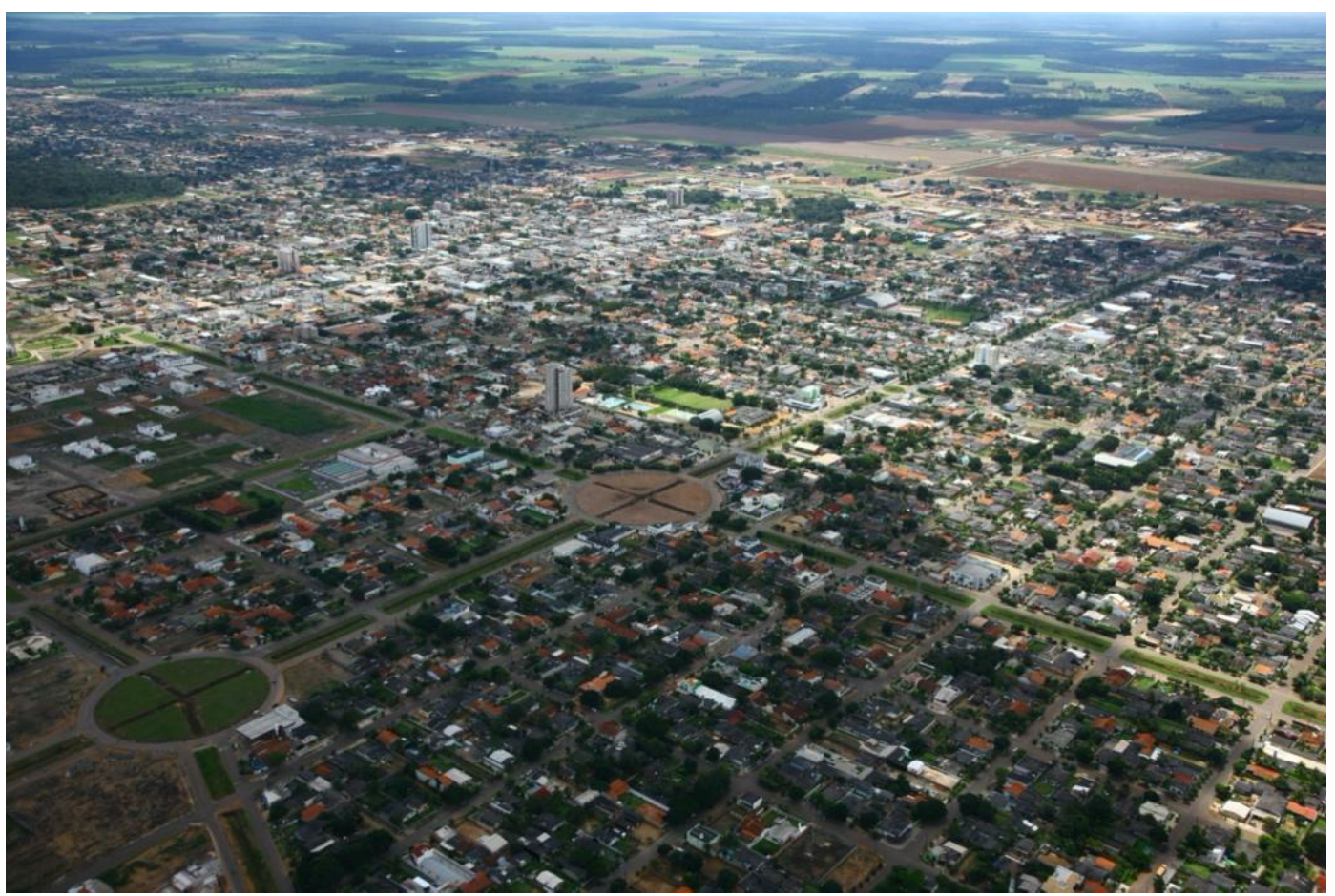

Fonte: Colonizadora SINOP, 2009. 
Como um múltiplo estudo de caso, neste artigo foram preferivelmente considerados aqueles empreendimentos que, de modo sistematizado, criaram várias cidades próximas e interligadas e que, por tanto, lidaram com um conjunto urbano e tiveram a chance de tratar do planejamento de toda uma região. Como se conformaram estes novos conjuntos urbanos é uma questão secundária que perpassa este trabalho. Desse modo, são arrolados aqui os planos e esquemas da principal companhia colonizadora no Paraná - incialmente Companhia de Terras Norte do Paraná, depois denominada Companhia Melhoramentos Norte do Paraná (CMNP); da Colonizadora SINOP no Mato Grosso, com uma referência excepcional ao empreendimento singular da Companhia Colonizadora e Imobiliária Douradense no Mato Grosso do Sul; e do governo federal que, através do Instituto Nacional de Colonização e Reforma Agrária (INCRA), promoveu a ocupação urbana ao longo da rodovia Transamazônica nos anos 1970 com o projeto de dezenas de pequenas cidades. A CMNP fundou quase uma centena de cidades novas no norte paranaense entre os anos 1930 e 1960; a SINOP fundou quatro cidades no norte do Mato Grosso nos anos 1970 (Figura 1); Angélica, uma cidade isolada fundada em 1954 na gleba rural da Colonizadora Douradense, antecipou os preceitos do urbanismo de Brasília, constituindo um divisor de águas no urbanismo brasileiro.

A partir de estudos da forma urbana, da história da arquitetura e do urbanismo e da contextualização das novas cidades na dinâmica sociocultural do país, entrelaço fontes primárias e secundárias para construir meu argumento. Na primeira seção do artigo, aponto para a estreita relação entre os empreendimentos analisados e os planos e políticas governamentais de desenvolvimento. Na segunda seção, chamo atenção para o fato de que as cidades novas de colonização foram planejadas remotamente a partir de experiências metropolitanas em contextos urbanos consolidados. Reitero, na sequência, que as ideias urbanísticas empregadas nos novos traçados foram adaptadas. Na quarta seção constato que as cidades da primeira metade do século foram projetadas majoritariamente por engenheiros a partir de um urbanismo de caráter academicista, em contraposição às cidades da segunda metade do século, projetadas por arquitetos segundo o ideário do urbanismo funcionalista. Por fim, afirmo que a grelha foi o padrão recorrente nos traçados urbanos arquitetados ao longo do século passado.

\section{Desenvolvimento e Transformação Física do Território}

Os estudos de caso aqui reunidos mostram, cada um a seu tempo, que o desenvolvimento do interior do país correspondeu aos planos e políticas governamentais vigentes. Governos democráticos e ditatoriais insistiram igualmente na modernização e no desenvolvimento do Brasil a partir da transformação física do seu território, fruto de um "pensamento espacialista" que orientou a cultura política brasileira no século passado (MORAES, 2008, p. 91-101). A noção de civilização que marcara o Brasil Império (1822-1889) deu lugar à ideia republicana de modernização, permeando a era Vargas (1930-1945) e a administração de JK (1956-1961); essa ideia foi depois substituída pela noção de desenvolvimento no regime militar (1964-1985). Civilizar foi uma forma de qualificar a expansão territorial, que reafirmou as determinações da conquista colonial: apropriação da terra e submissão dos 'naturais'; modernizar significou, entre outras coisas, ocupar e reorganizar o território, conectar suas partes, dotá-lo de equipamentos (MORAES, 2008, p. 95-96).

A criação das novas capitais - Goiânia (1933-36), Brasília (1957-1961) e Palmas (1989) - atestou o empenho governamental em ocupar o território, desenvolver a nação e construir o país. Do mesmo modo, novas cidades no interior do Brasil foram tanto sinais de progresso quanto promotoras do desenvolvimento regional (REGO, 2020; REGO, 2017a). Uma ideia prevalecente de cidade e uma forma urbana correspondente marcaram, sucessivamente, as frentes pioneiras estimuladas pelas políticas governamentais, como veremos a seguir.

O governo Vargas almejou a criação de uma nova sociedade como parte de um país moderno, industrializado e urbano, e o Estado Novo foi uma fase importante para o capitalismo industrial 
brasileiro, com a passagem de uma economia agrícola de exportação para uma economia urbanoindustrial. (REZENDE, 2012, p. 12; GOMES, 2013, p. 43). No momento em que uma expressiva modernização passava a marcar o Brasil, a arquitetura modernista foi tomada como imagem do projeto para um país moderno, e constituiu um dos seus símbolos mais emblemáticos (MARTINS, 2010; GORELIK, 2005; CAVALCANTI, 2010). Entretanto, a produção da arquitetura e das artes, antenada na vanguarda europeia, fomentava a identidade nacional por meio da valorização do aspecto regional e da tradição local, associando o particular e o universal, o habitual e o novo.

Com setenta e sete por cento do território nacional então economicamente inexplorado (WAIBEL, 1955, p. 389), a política da Marcha para Oeste (RICARDO, 1959) estimulou a ocupação do interior do país nos anos 1940, sustentada pelo comércio internacional do café e o capital global, e promoveu a criação de novas cidades e a construção de estradas e ferrovias. A criação de cidades planejadas nas fronteiras agrícola instalava a modernidade, fazendo da modernização o seu efeito - e não oposto. A inauguração da nova capital de Goiás em 1942 ilustrou esta política do governo federal, autoritário e centralizador, que exaltava a ocupação territorial do passado para fomentar o desenvolvimento do interior do país. O traçado de Goiânia, cuja versão final fazia ressoar o projeto da cidade jardim da era do automóvel, foi apresentado como o resultado da expansão do capitalismo na nova era da economia nacional (REGO, 2020). A colonização privada do norte do Paraná e a decorrente criação de novas cidades naquela região também estão inseridas neste contexto e não foram indiferentes a ele. Temos aí cidades que nasceram planejadas, portanto modernas, respondendo a um urbanismo que reelaborou padrões urbanos tradicionais e modelos tomados da história das cidades, a partir da noção de arte urbana - que abordarei mais adiante.

A criação da cidade de Angélica, em 1954, antecipou, como disse anteriormente, o urbanismo funcionalista de Brasília e, tal como a nova capital federal, propôs uma imagem urbana moderna para o interior do país. A interiorização da capital do Brasil era parte do Plano de Metas de Juscelino Kubitschek que, em 1955, havia proposto acelerar o desenvolvimento nacional. Brasília foi inaugurada em 1960, no começo da década do desenvolvimento. Com o slogan de 50 anos em 5, JK implantou um modelo econômico que favoreceu a associação de companhias privadas brasileiras com corporações estatais e multinacionais e que foi bem-sucedido no curto prazo, alcançando uma taxa de crescimento de 10\% ao ano (ALMANDOZ, 2015, p. 92; DEL PRIORE e VENANCIO, 2010, p. 268). A consequente industrialização do país acarretou a explosão demográfica nas principais cidades brasileiras, assim como ocorrera no governo Vargas nos anos 1940 (DEL RIO, 2009, p. 8). A Brasília - e também a Angélica, ainda que em escala menor - correspondia criar uma nova ordem social por meio de uma forma urbana inovadora, própria destes novos tempos, que desfamiliarizou e reconceituou a vida na cidade (GORELIK, 2005, p. 49; HOLSTON, 1989; REGO, 2017b; REGO, 2020). Aí passamos a perceber uma forma urbana radicalmente nova, menos vinculada à tradição e aspirante à ambiência universal da cidade funcional. Em geral, a modernidade passou a engendrar um "nacionalismo internacionalista", que não mais se reportava a regionalismos ou à tradição local (VIDAL, 2009, p. 196 e 189; ALMANDOZ, 2015, p. 105).

O regime militar aplicou um modelo de desenvolvimento semelhante, e novamente o esforço para construir o país focou na ocupação territorial e na integração nacional, qualificando os aparatos produtivos e as infraestruturas (MORAES, 2008, p. 100; BRASIL, 1971; CARDOSO e MÜLLER, 2008). Durante a ditadura, iniciativas para transformar 0 ambiente físico estimularam o crescimento econômico e o desenvolvimento regional e o começo dos anos 1970 ficou conhecido como o período do "milagre econômico", quando o PIB saltou de 9,8\% para 14\% em 1973. Obras como a construção da rodovia Transamazônica, da ponte Rio-Niterói e da hidrelétrica de Itaipu foram tomadas como expressão do avanço, e em certa medida fizeram reviver a euforia dos tempos de Brasília (ALMANDOZ, 2015, p. 115; DEL PRIORE e VENANCIO, 2010, p. 284). Embora não tenha construído uma cidade capital, o governo militar planejou uma série de novas cidades ao longo da 
Transamazônica por meio do plano de colonização e assentamento rural que almejava desenvolvimento regional, transformação social e integração nacional. Traçados modernistas permitiriam o nascimento de uma "nova civilização" e, com isso, perdurou a imagem da cidade transformada, desvencilhada de tradições e velhos padrões urbanos, mesmo com a sinalização contemporânea de superação destas ideias urbanísticas.

\section{Experiências Metropolitanas Alheias e Adaptação Seletiva}

Cidades novas são atos calculados, e nelas não há nada de espontâneo ou voluntário: são inconfundíveis sinais de hegemonia (WAKEMAN, 2016, p. 1) - um pensamento que também vale para as cidades novas planejadas nas frentes pioneiras de colonização agrícola no Brasil do século XX, como vimos na seção anterior. Estas iniciativas de colonização interna, encetada por pessoas do próprio país e incentivadas pelos dirigentes nacionais, tratou de povoar, desenvolver e explorar progressivamente distintas partes do país. Nesse sentido, como todo processo de colonização, elas promoveram o enxerto de uma certa cultura em um sítio estranho (KOOLHAAS, 1994, p. 245).

Reconheço aqui que "a história das cidades brasileiras é também a história das cidades europeias e norte-americanas, na medida em que certas formas de vida e de mentalidade que se desenvolvem naquelas cidades as transcendem e exercem uma ação decisiva sobre toda a sua área de influência" (REGO, 2019, p. 8; ROMERO, 2009; REGO, 2011). É nesse sentido que chamo atenção para a viagem transnacional das ideias que acabaram sendo enxertadas nos projetos de novas cidades. Nesta viagem, há que se considerar o estágio intermediário entre o que pode ser seu ponto de origem - o conjunto das circunstâncias originais em que elas entraram para o discurso urbanístico - e sua materialização nas condições em que aparecem nas novas cidades no interior do Brasil. Este estágio é o que Said (1983, p. 157) entendeu como "a passagem pela pressão de contextos diversos" rumo a outros tempos e lugares.

Figura 2: Perspectiva da zona residencial de Angélica-MS, projeto do arquiteto Jorge Wilheim, 1954. Destaca-se a faixa central comunitária da unidade de vizinhança na conformação da cidade funcional.

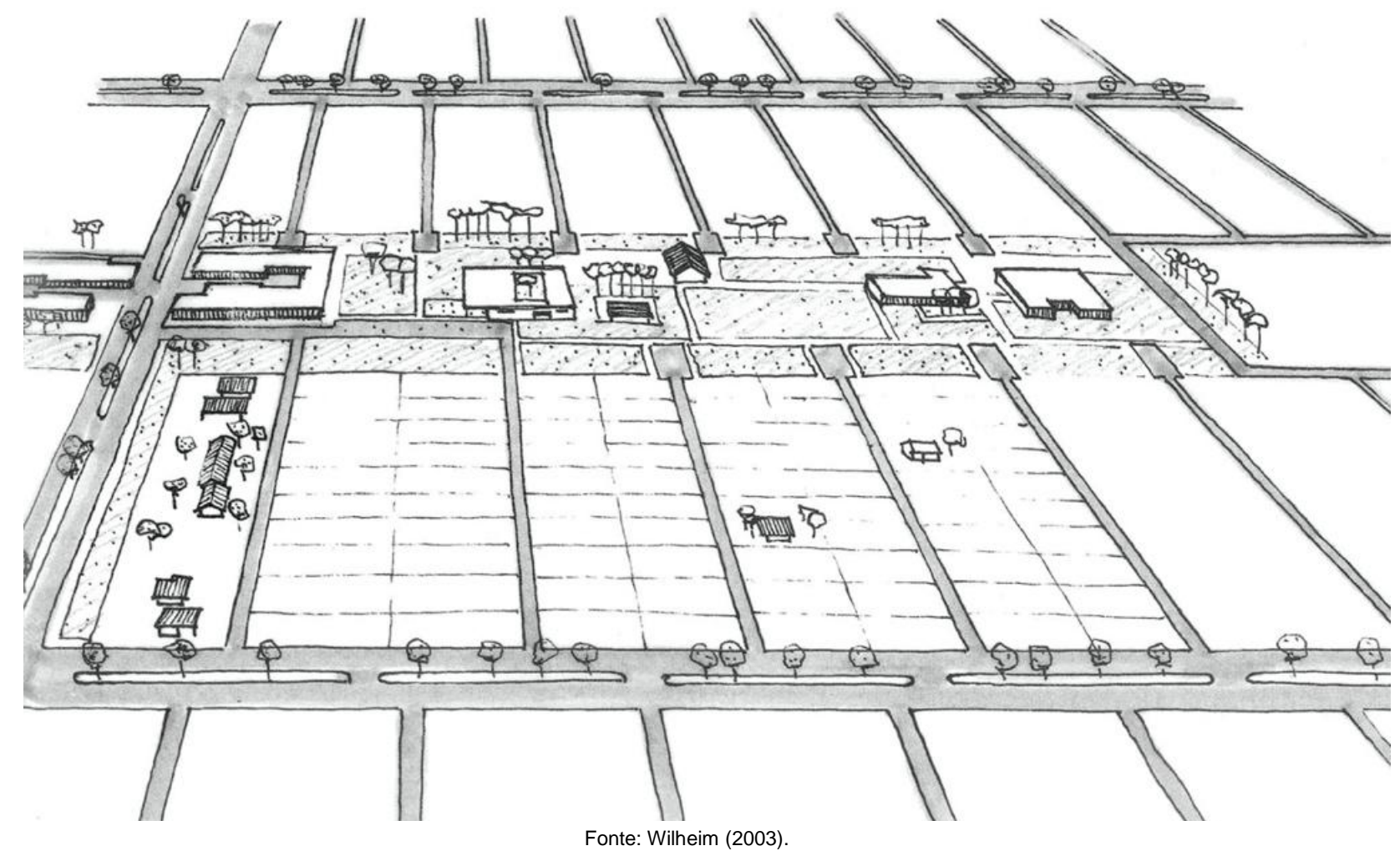


As cidades aqui consideradas foram projetadas, em sua maioria, em centros urbanos consolidados, a partir de ideias desencadeadas por experiências urbanas e metropolitanas, dos próprios projetistas ou de outrem. Como exemplo, cito a ideia de unidade de vizinhança, formulada no Estados Unidos como parte do desdobramento local do ideário britânico da cidade jardim, e depois incorporada ao repertório do urbanismo funcionalista europeu em versão menos pitoresca e mais regular e geométrica. A unidade de vizinhança é a base do traçado de Angélica, uma cidade para vinte mil habitantes projetada desde São Paulo para o interior agrícola do então Mato Grosso (hoje Mato Grosso do Sul. Figura 2). Em perspectiva, a proposta parece hoje pouco apropriada para o seu contexto; apenas na metrópole paulista se poderia imaginar sugerir piquenique na vasta área verde livre do interior das superquadras de Angélica, dados o clima e o contexto local (WILHEIM, 2003, p. 33). Não foi à toa que estas áreas verdes livres acabaram ignoradas pela população e parceladas: de fato, uma prática cultural alheia só é efetivamente aceita se ela fizer sentido no seu novo contexto social (TOTA, 2000).

Figura 3: Detalhe da planta de Cianorte-PR, projeto do engenheiro civil Jorge de Macedo Vieira, 1953. Destaca-se a composição de vias, espaços livres, vegetação e edificações em um urbanismo híbrido - pitoresco e regular, formal e informal.

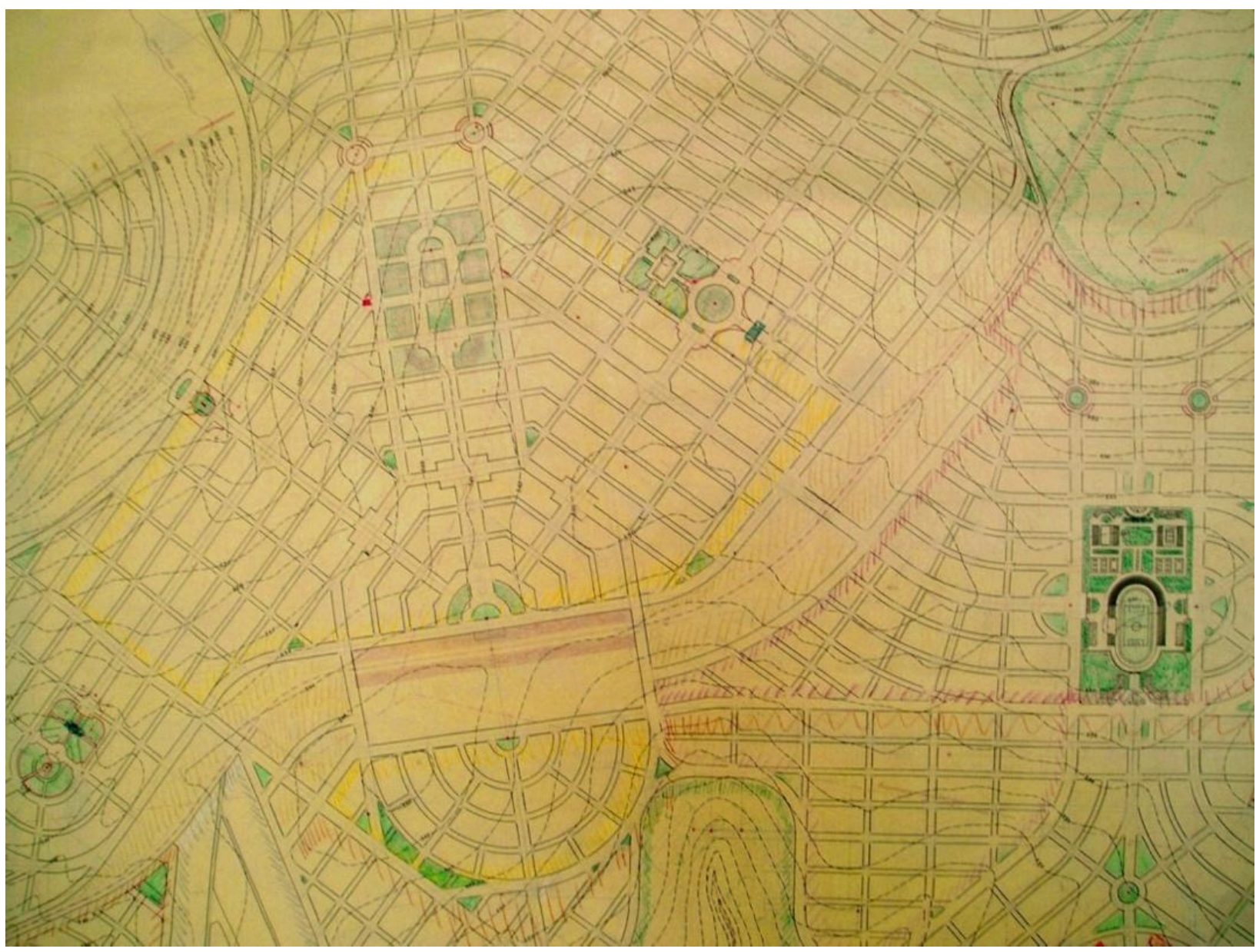

Fonte: Rego (2019).

Ainda assim, nos traçados destas cidades novas são detectáveis a adaptação seletiva, a transformação e o hibridismo intrínsecos ao processo de circulação das ideias (WARD, 2018; HEALEY e UPTON, 2010; HEIN, 2017; HOME, 2018; SAID, 1983; REGO, 2019; WARD, 2010; WARD, 2000). Este aspecto é parte da "fertilização cruzada" da história do urbanismo (SUTCLIFFE, 1981, p. 163; CALABI, 2012) e, a priori, não significa um fator negativo. Os traçados de Maringá (1945-1947) e de Cianorte (1953. Figura 3), por exemplo, foram reconhecidos como fruto de um urbanismo híbrido, que associou princípios formais da cidade jardim e do City Beautiful, em composições tipicamente Beaux Arts (BONFATO, 2008; REGO, 2012). O traçado de Rurópolis e das demais projetadas ao longo da 
Transamazônica, por sua vez, associou a unidade de vizinhança e preceitos da cidade funcional ao ideário da cidade jardim, como se viu também em projetos coetâneos de New Towns inglesas, que combinaram a tradição da cidade jardim com o apreço pelo o desenho moderno (REGO, 2019; REGO, 2017b; GOLD, 2008). Insistindo na questão da adaptação, lembro ainda que em Angélica, as ideias da Carta de Atenas foram aplicadas com o rechaço à alta densidade, pertinente ao pensamento dos CIAMs.

\section{Planejamento Regional}

Os esquemas da colonização privada do norte do Paraná e do Mato Grosso, assim como o do empreendimento estatal ao longo da Transamazônica, produziram conjuntos de cidades, cujo posicionamento, número, tamanho e eventual hierarquia estavam atrelados ao parcelamento rural a ser implementado, às particularidades geográficas e à construção da infraestrutura de transporte. Configuravam-se assim experiências de planejamento regional que contaram com um potente precedente teórico: o ideário cidade jardim, sua proposta de descentralização e desconcentração e consequente constituição de uma "região urbana" (WARD, 1992, p. 10) - um precedente que também serviu ao planejamento do distrito federal, como demonstrou Derntl (2016). ${ }^{1}$ Nestas regiões, não houve a tradicional evolução do rural ao urbano: as cidades vieram antes.

A colonização do norte do Paraná iniciada no final dos anos 1920 por uma companhia britânica implantou uma série de cidades ao longo da ferrovia, também construída por ela. Estas cidades eram independentes e equivalentes no tamanho, na infraestrutura e nos serviços que ofereciam; estavam limitadas por cinturões verdes que coincidiam com as nascentes adjacentes às áreas urbanas; e regularmente distanciadas, de modo que um morador da zona rural poderia chegar a pé à cidade mais próxima. A proximidade entre cidades, amparada no parcelamento de pequenas propriedades rurais, assegurava a inexistência de latifúndios e o casamento entre cidade e campo fomentava a vitalidade urbana. Este esquema fazia ressoar a ideia howardiana de cidades sociais, adaptada a um empreendimento privado com o descarte do seu propósito social original (REGO, 2019; REGO, 2011; HOWARD, 1965. Figura 4).

Figura 4: As cidades fundadas pela companhia britânica no norte do Paraná, a partir do esquema de cidades sociais. Vê-se, da direita para a esquerda, Apucarana, Pirapó, Jandaia e Mandaguari, conectadas pela ferrovia. Destaca-se o traçado simétrico de Pirapó.

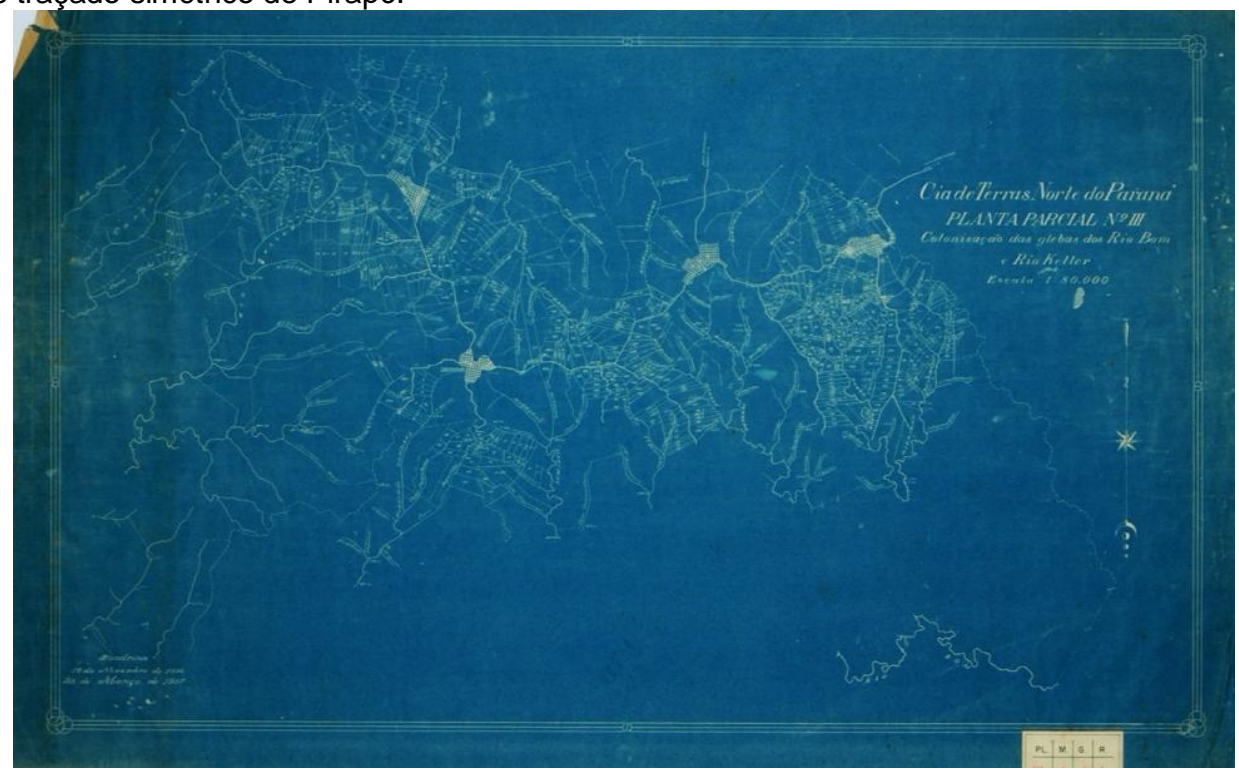

Fonte: Museu da Imigração do Estado de São Paulo, 1936-37.

\footnotetext{
${ }^{1}$ A noção de região urbana está atrelada à inter-relação entre cidades, como numa rede urbana, mas é mais dependente da proximidade entre elas.
} 
A direção brasileira do empreendimento, com a saída dos acionistas britânicos em 1944, ajustou o esquema de colonização para constituir uma estrutura urbana hierarquizada, com mais autonomia em relação à ferrovia, então estatizada. Assim foram criados quatro centros regionais ao longo da ferrovia e, entre eles, cidades menores; na verdade, essas eram as cidades fundadas pela administração anterior (Figura 5). E entre elas, foram implantados distritos e patrimônios que orbitavam em torno dos núcleos maiores, expandindo espacialmente o povoamento antes linear. Como cidades satélites - um modelo urbanístico então globalmente difundido - quase uma centena de pequenas cidades foram implantadas no norte paranaense, mais rapidamente e com menos custos. Surgiu desse modo, por toda a região, uma constelação de cidades hierarquizadas, dependentes, próximas e interligadas (REGO, 2019; COMPANHIA, 1975).

Figura 5: Projeto de Lovat-PR (hoje Mandaguari), elaborado pelo escritório técnico da Companhia de Terras Norte do Paraná, 1937, possivelmente desenvolvido pelo agrimensor russo Alexandre Razgulaeff. Imagem da cidade composta por padrões urbanos tradicionais em arranjos artísticos clássicos: vistas, formalidade e conjunto.

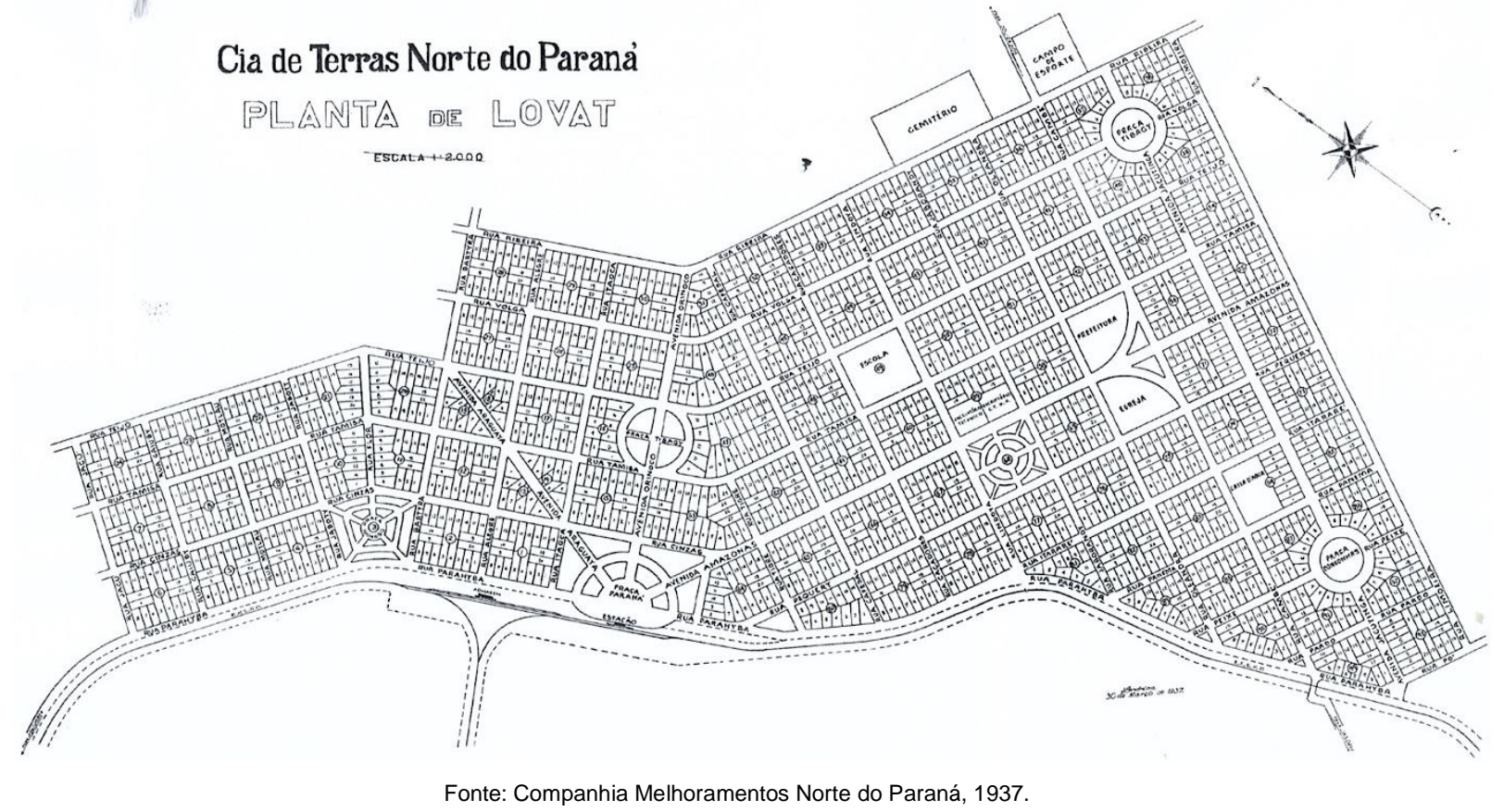

Estudo sobre a colonização privada do oeste paranaense, também responsável pela criação de um conjunto de cidades, tomou o empreendimento norte-paranaense como modelo. O povoamento linear no oeste do Paraná, menos regular pela variação no relevo, obedeceu a vias preexistentes, mas a cultura de subsistência almejada diminuiu a relevância das cidades no plano de colonização, que mostram uma conformação menos elaborada e mais simplificada (OLDONI, 2016).

O esquema norte-paranaense de colonização e urbanização também serviu de modelo para o Urbanismo Rural, um plano de colonização que constituiu a diretriz do INCRA para empreendimentos privados e estatais na Bacia Amazônica nos anos 1970 (CAMARGO, 1973; CAMARGO, 1963; KATZMAN, 1977; REGO, 2019; REGO, 2017a; REGO, 2015. Figura 6). Seguindo esta diretriz, a Colonizadora SINOP - a Sociedade Imobiliária Noroeste do Paraná, que havia implantado novas cidades no Paraná seguindo o padrão urbano da companhia britânica, fundou a cidade de Sinop e quatro 'satélites' no norte do Mato Grosso, que deveriam ser intermediados por bairros rurais, ou seja, núcleos subsidiários (COLONIZADORA, 1972). Os lotes rurais tiveram dimensões maiores que as praticadas no Paraná e o fato de Sinop estar posicionada junto da rodovia Cuiabá-Santarém, enquanto as demais cidades estão afastadas dela, fez com que o conjunto urbano tivesse um desenvolvimento menos equilibrado que o experimentado no norte paranaense. 
Figura 6: O esquema do Urbanismo Rural aplicado ao traçado linear da Rodovia Transamazônica, projeto do arquiteto José Geraldo da Cunha Camargo, 1973. Constelação de satélites em torno de núcleos urbanos principais.

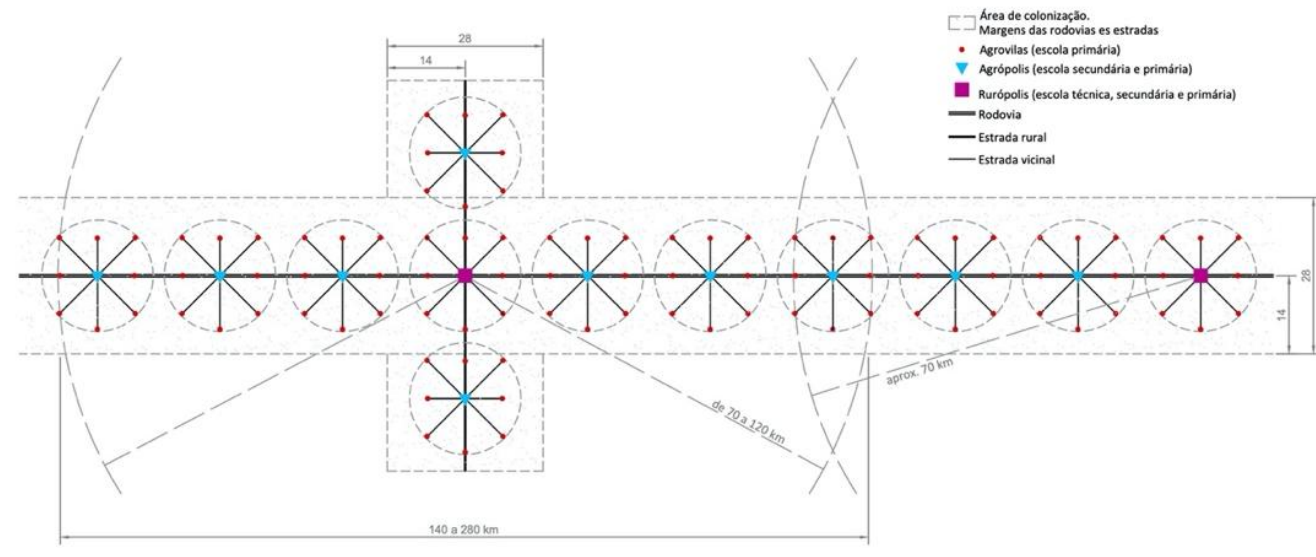

Fonte: Rego (2019).

As cidades plantadas pelo INCRA ao longo da rodovia Transamazônica seguiram a mesma diretriz de planejamento regional. Reiterava-se assim a proposta de descentralização urbana e entrosamento entre cidade e campo, com a estrutura hierarquizada de quatro tipos de núcleos urbanos, definidos pelos serviços e pelo grau de escolaridade que cada um oferecia. Quanto maior fosse o tipo urbano menor era o seu número nesta rede de cidades. Desse modo, o esquema do INCRA previa que um certo número de "agrovilas" funcionasse como satélites de uma "agrópolis" (Figura 7), a fim de ter complementadas suas necessidades sociais e econômicas; e cada conjunto de "agrópolis" e "agrovilas" seria dependente de uma "rurópolis", por sua vez dependente da cidade próxima. 
Figura 7: A agrópolis Brasil Novo-PA, projeto do arquiteto José Geraldo da Cunha Camargo, 1973. Implementação da cidade funcional.

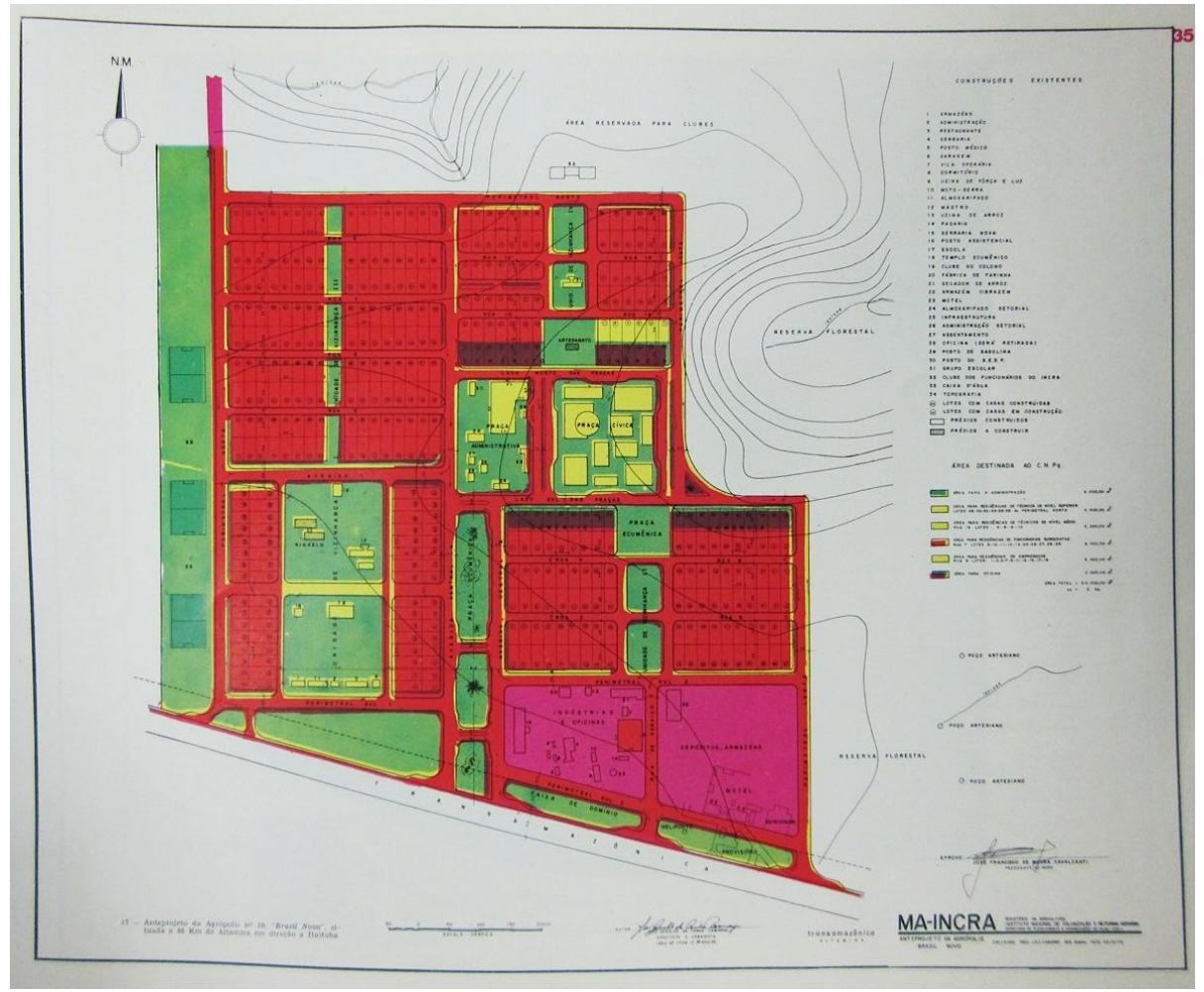

Fonte: Camargo (1973).

Contudo, fatores diversos contribuíram para uma sorte diferente daquela que teve o modelo paranaense (REGO, 2017a). As novas cidades transamazônicas, de beira de estrada, divergiam da cultura urbana ribeirinha da região, com um padrão de ocupação territorial distinto e desvinculado da acessibilidade fluvial tradicional. Contavam ainda com formas urbanas radicalmente novas, rígidas na configuração e na segregação das funções urbanas, e totalitárias no controle da vida urbana.

\section{Arte Urbana Versus Cidade Funcional}

No caso das cidades novas, o urbanismo frequentemente se dá como projeto de um artefato, construído, muitas vezes, apenas bidimensionalmente. Em alguns casos, croquis e perspectivas sobrepostos às plantas denotam uma consideração mais holística do desenho urbano, ainda que rudimentar ou näif. Deste modo, envolvem não apenas o parcelamento do solo urbano, a indicação do número, da posição e do tamanho dos espaços livres e o arranjo artístico das vias, mas também a inserção de edificações públicas proeminentes e o tratamento da arborização urbana viária.

Com efeito, o urbanismo difundido nas escolas de engenharia, através de disciplinas como Traçado de Cidades, e praticado por engenheiros, topógrafos e agrimensores que majoritariamente projetaram as novas cidades no Brasil da primeira metade do século XX, pode ser entendido como um urbanismo academicista (ALMANDOZ, 2013, p. 25; PINHEIRO, 2009; PINHEIRO, 2010; REGO, 2019).

O termo urbanismo academicista, assim como Art Urbain e as designações equivalentes - Art Public, Civic Art, Stadt-Baukunst, e City Beautiful - recolhe aquelas manifestações da cultura urbanística do início do século XX que privilegiavam os princípios artísticos nos projetos de transformação das 
cidades (CALABI, 2012, p. 100). A arte urbana, de acordo com a historiadora Françoise Choay, ao tomar a cidade como sendo mais que um aglomerado de edificações,

a introduit dans les ville occidentales la proportion, la régularité, la symétrie, la perspective, en les appliquant aux voies, places, édifices, au traitement des leurs rapports et de les leurs éléments de liaison (arcades, colonnades, portes monumentales, arcs, jardins, obélisques, fontaines, statues, etc.). On lui doit la notion de composition urbaine, dérivée de la peinture (VOCABULAIRE, 2010, p. 13).

Desse modo, os vários componentes da forma urbana são tratados como elementos de uma composição artística, segundo preceitos acadêmicos clássicos. Com apurada noção de conjunto e harmonia, são combinados, por exemplo, ruas, avenidas, rotatórias; bulevares, aleias, passeios e arborização viária; quadras, edificações e alinhamento predial; praças, parques, jardins, esplanadas, belvederes; entrada e centro da cidade; monumentos e fontes. Com efeito, se alcançava a beleza urbana com certos motivos formais e padrões de desenho que valorizavam a arte, a arquitetura e seus princípios - o que pode notar em muitas das cidades novas projetadas por engenheiros no norte do Paraná (REGO, 2012, p. 164. Figura 8). O trabalho do urbanista consistia, portanto, em um esforço para se fazer pela cidade o que um arquiteto fazia por uma edificação, o que deixava o urbanismo essencialmente arquitetônico. Era a continuação da arquitetura em uma dimensão maior, uma extensão da esfera de influência do arquiteto.

Consoante com este urbanismo academicista, o traçado das novas cidades do norte paranaense é geralmente um artefato finito, regular, quase sempre simétrico, perfeito na forma e congelado na sua configuração ideal. Colin Rowe (1976) associou a utopia, entendida como uma orientação que transcende a realidade, à imagem clássica da imutabilidade. A utopia, assim como a obra de arte clássica, instrui, civiliza e edifica a sociedade exposta a ela. Na sua finitude, acabamento, harmonia e regularidade, e na sua indiferença à mudança, ao crescimento e ao movimento, o traçado de uma cidade nova não esconde seu aspecto essencialmente utópico, cristalizado na perfeição da forma e na monotonia esquemática da cidade ideal.

Figura 8: Projeto de Ivaiporã-PR, engenheiro civil Yaroslau Sessak, 1953. A cidade artisticamente desenhada a partir da malha ortogonal e sua adaptação ao sítio.

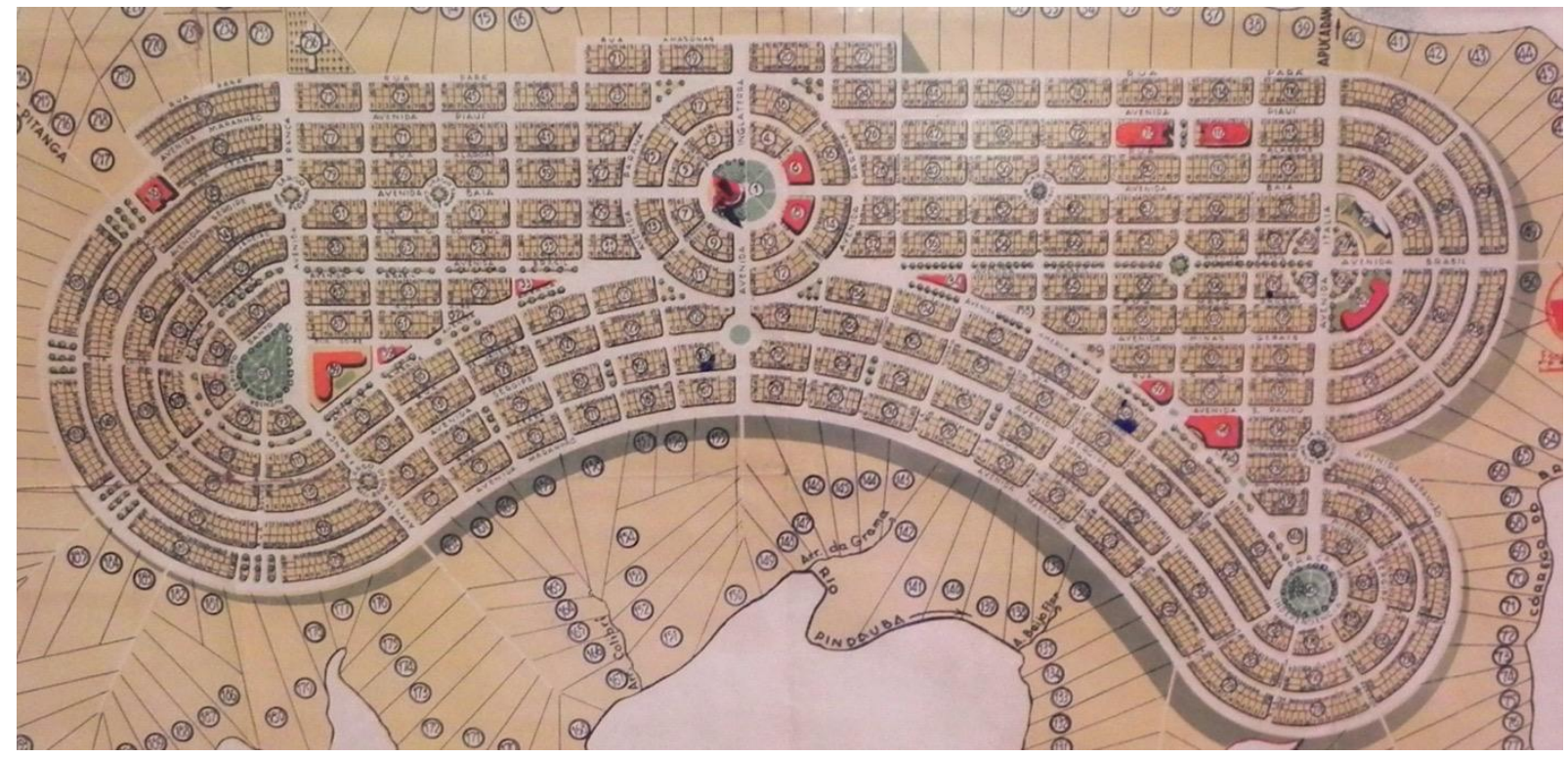

Fonte: Prefeitura Municipal de Ivaiporã (1953). 
Rowe já havia demonstrado antes como a arquitetura modernista estava enraizada na tradição clássica. Sem contradizê-lo, Rigotti (2016) revelou que o projeto de Le Corbusier para Buenos Aires (1929 e 1937) era decorrente, por um lado, da interpretação da geografia local e, por outro, da aplicação de noções acadêmicas de composição. Corbusier comungava como os princípios (mas não com as soluções) Beaux Arts. Sua proposta portenha é essencialmente arquitetônica e, na sua dimensão artística clássica, limites, centralidade, unidade e simetria se mostram tópicos fundamentais da composição. E isso é especialmente notado nas cidades criadas na colonização privada do norte paranaense.

Entretanto, o traçado das novas cidades se fez mais aberto e indiferente às normas clássicas da composição artística na segunda metade do século passado, quando apareceram os trabalhos dos egressos dos primeiros cursos de arquitetura e urbanismo - e Angélica marca esta mudança. Os projetos urbanos desenvolvidos por arquitetos nas frentes pioneiras de colonização do centro-oeste e norte do país consolidaram a hegemonia do urbanismo funcionalista. Mesmo Sinop, cujo projeto foi revisado tomando Maringá, no Paraná, como referência, revela aspectos do urbanismo de Brasília, como a largura das vias e o papel do automóvel na conformação urbana. Pois, a rigor, o discurso do urbanismo dos Congressos Internacionais de Arquitetura Moderna (CIAMs) excluiu a cidade jardim, a configuração Beaux Arts e todo tipo de formalismo explícito inadequado às necessidades modernas (MUMFORD, 2000). Os CIAMs se diferenciaram do urbanismo tradicional - o então urbanismo academicista - e defenderam um urbanismo moderno como antítese a tudo que existiu previamente. A Carta de Atenas, um produto dos CIAMs, simplificou e segregou as principais funções da cidade morar, trabalhar e recrear-se, que foram conformadas de modo a serem conectadas pelo automóvel. Os trabalhos apresentados nos CIAMs combinaram as estratégias abstratas da arte moderna com a celebração de novas técnicas construtivas. Sua abordagem racionalista/funcionalista, consoante com os princípios fordista e taylorista de fabricação em massa, favorecia o conhecimento científico e a objetividade por sobre valores, contexto e contribuições locais. Assim a cidade funcional significou uma racionalidade totalizadora, que redefiniu a organização espacial e a vida urbana, e criou tipologias novas como instrumento de mudança social e determinismo ambiental.

É nesse sentido que cabe a questão levantada por Lefebvre (2007, p. 150):

Will people be compliant and do what the plan expects them to do, shop at the shopping center, asking for advice at the device bureau, doing everything that civic center officers demand of them like good, reliable citizens?

A resposta pode ser percebida nas imagens e nos relatos das mudanças ocorridas em muitos traçados de cidades novas recém implantados. Formas urbanas radicalmente distintas da prática cultural, como a unidade de vizinhança, por exemplo, acabaram sendo apagadas da cidade, com a abertura de vias nas áreas livres de convivência interna às superquadras e/ou seu parcelamento, como se pode notar em Angélica e em Rurópolis - o que também ocorrera em Goiânia (REGO, 2019).

\section{A Grelha}

De toda sorte, a grelha foi o padrão de traçado urbano que prevaleceu nas cidades novas planejadas nas frentes de colonização aqui consideradas, tanto nos layouts consoantes com os princípios da arte urbana quanto nas "cidades funcionais". Mesmo no caso de Maringá e Cianorte, duas cidades conformadas a partir dos princípios formais da cidade jardim, o traçado urbano associou o pitoresco e o geométrico, o formal e irregular. Poucas cidades no Brasil foram projetadas com um traçado exclusivamente orgânico (TREVISAN, 2009). Em geral, em cidades de especulação fundiária a grelha foi aplicada por razões práticas: tratava-se de um instrumento conveniente à comoditização do espaço - e nos casos aqui estudados não foi diferente. 
Figura 9: Aerofoto de Lobato-PR, 1980. A cidade aparece antes do mundo rural constituir-se, e seu traçado ortogonal, embora esquemático, materializa noções da arte urbana.

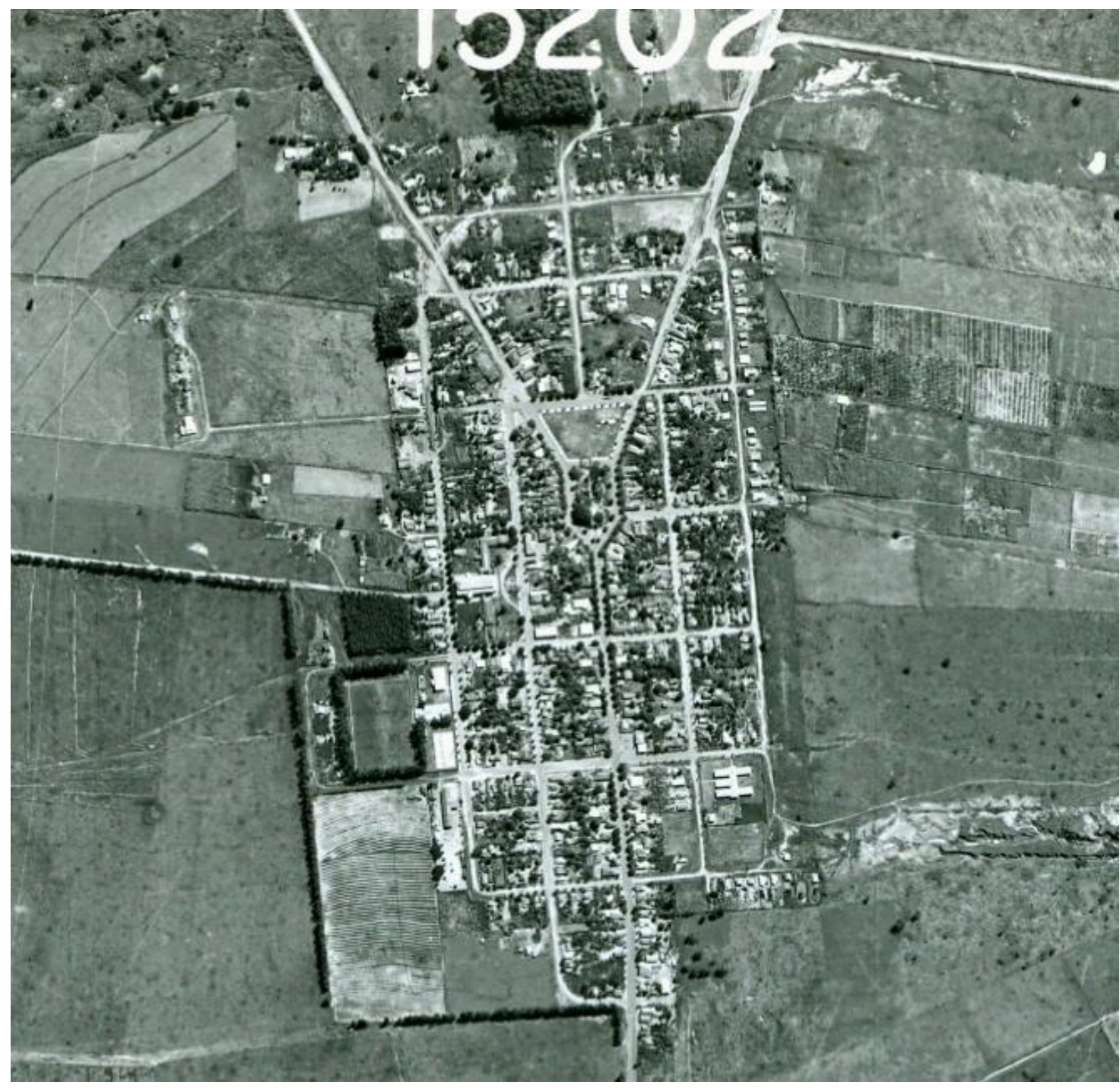

Fonte: Instituto de Terras, Cartografia e Geografia do Paraná, ITCG, 1980.

Contudo, o uso criativo da grelha é notável nas cidades novas do norte do Paraná (ROSANELLI, 2014), precisamente naquelas cidades projetadas por engenheiros na primeira metade do século, cuja formação recorreu aos ensinamentos da arte urbana. O traçado mais artístico destas cidades evitava os efeitos desfavoráveis do padrão reticulado, indistinto e indiferente. Pois definiam o formato da cidade consoante com as particularidades do sítio; evidenciavam o coração da cidade estabelecido no centro geométrico da forma urbana; aí criavam um centro cívico com a composição de edifícios, espaço livre, ornamentos e vegetação, respaldado por uma configuração das vias principais que recorria a motivos formais clássicos, como o trivium (Figura 9). Assim, o traçado da cidade se tornava singular, se especializava com estes arranjos artísticos, frente à generalidade e abstração que são características da retícula simples (REGO, 2019, p. 41). O template sugerido previamente pela adoção da grelha, customizado através do ajuste às particularidades do sítio e especializado pela inserção de elementos morfológicos com tratamento artístico, permitiu a harmonia entre o natural, o prático, o artístico e o simbólico.

A abordagem academicista do urbanismo e sua noção de cidade bela acabaram suplantados pelo urbanismo racionalista e sua cidade funcional. A abordagem funcionalista da forma urbana em geral a privou das qualidades artísticas. As novas cidades do período pós-Brasília, traçadas em sua maioria por arquitetos, continuaram apresentando um traçado reticulado mas, por vezes, com uma 
conformação seriada, produzida mecanicamente, indistinta nas suas partes padronizadas (Figura 8). 0 centro cívico, classicamente entendido como o espaço intersticial no conjunto de edificações posicionado no coração da cidade, deu lugar a um eixo de extensão verde, com edificações isoladas e dispersas, sem efeito de conjunto, como se vê no traçado original de Rurópolis e de Angélica. As praças, como em Brasil Novo, ganharam especificidade pela função que desempenham na vida urbana- praça ecumênica, praça cívica, praça administrativa-, mas formalmente não mereceram tratamento específico.

\section{Conclusões}

A visão histórica, ampla e comparativa, com a qual se observou os casos indicados neste estudo, permitiu reconhecer que as novas cidades criadas nas frentes de colonização do Brasil do século $X X$ materializaram ideias urbanísticas em circulação global. A evolução do pensamento urbanístico pôde ser notada através das formas urbanas consideradas, das permanências de certas noções e padrões urbanísticos assim como o rechaço de outros. Neste caso, a evolução nem sempre significou melhoria. A forma urbana de algumas destas novas cidades acabou parcialmente rejeitada e transformada, especialmente em conformações menos tradicionais, como foi o caso das unidades de vizinhança em Angélica e Rurópolis. Esta visão ampla e comparativa pode contribuir para uma revisão das vertentes do urbanismo produzido no século passado e para o modo como hoje fazemos cidades ou partes delas, precisamente quando se constata o vigoroso empobrecimento das formas urbanas.

A visão retrospectiva de conjunto nos mostrou que no norte do Paraná a construção das cidades precedeu a venda dos lotes rurais parcelados nas suas imediações. O mesmo se deu na colonização do norte do Mato Grosso aqui estudada. No norte paranaense a cafeicultura e a dimensão dos lotes rurais corresponderam ao papel designado às cidades planejadas como entreposto comercial e centro de serviços. A agricultura extensiva, no entanto, acabou por desviar o papel das cidades satélites no esquema de colonização no norte mato-grossense. Na Transamazônica, cidades e lotes rurais foram estabelecidos praticamente ao mesmo tempo e o empreendimento de colonização gigante não foi implantado gradualmente, o que comprometeu o seu desenvolvimento. Sem a infraestrutura inicialmente prevista, cidades novas e zona rural na Transamazônica acabaram abandonadas. De toda sorte, nos três casos o papel das cidades próximas, dependentes e interligadas era dar subsídio à atividade rural. Estas cidades foram criadas em função do campo.

Nos três casos estudados, nota-se a continuidade de uma mesma ideia de configuração espacial regional, mesmo porque os dois últimos casos tomaram o primeiro como modelo bem-sucedido. Neles foram configuradas regiões urbanas, a partir do ideário garden city, com cidades principais e satélites próximos e dependentes, compartilhando serviços e infraestrutura. É interessante notar como a colonização alo longo da Transamazônica associou o ideário da cidade jardim, no nível regional, com preceitos do CIAM na conformação das cidades. Em certa medida, isso também pode ser notado no planejamento do Distrito Federal e no traçado das cidades satélites de Brasília.

A proposta da forma urbana, em contrapartida, mostra ruptura na sequência dos casos estudados. $O$ traçado inovador de Angélica marca esta ruptura, com a adoção de ideias da cidade funcional e da configuração racionalista da superquadra - antes da criação de Brasília-, que então já se tornavam hegemônicas. Corresponde ainda à liderança e supremacia do arquiteto no projeto e planejamento urbano. Antes disso, a cidade conformada com arranjos formais clássicos e tratada como arte urbana prevaleceu em projetos majoritariamente desenvolvidos por engenheiros. A sorte destas cidades e das três regiões urbanas que elas originalmente formaram foi bastante diversa e ainda está para ser estudada a evolução da proposta de cidades satélites nelas aplicadas. 


\section{Agradecimentos}

Este artigo é desenvolvimento da palestra proferida no ciclo de tertúlias promovido pelo Grupo de Pesquisa em História do Urbanismo e da Cidade, da UnB. Agradeço a Rodrigo de Faria e a Carolina Pescatori pela oportunidade de divulgação deste trabalho. Agradeço também aos revisores deste artigo, cujas contribuições foram instigantes e construtivas. A pesquisa da qual se desenvolveu este artigo é financiada pelo CNPq.

\section{Referências}

ALMANDOZ, A. Modernization, urbanization and development in Latin America, 1900s-2000s. Londres: Nova York: Routledge, 2015.

ALMANDOZ, A. Modernización urbana en América Latina. De las grandes aldeas a las metrópolis masificadas. Santiago: Instituto de Estudios Urbanos y Territoriales, 2013.

ANDRADE, C. R. M. A circulação transatlântica da ideia de cidade jardim: as referências teóricas dos urbanistas brasileiros na primeira metade do século XX. In: SALGADO, I. e BERTONI, A. (orgs.). Da construção do território ao planejamento das cidades: competências técnicas e saberes profissionais na Europa e nas Américas. São Carlos: RiMA, 2010. p. 27-33.

ANGOTTI-SALGUEIRO, H. e SIMÕES JUNIOR, J. G. Por uma reflexão sobre pioneiros do urbanismo no Brasil e modalidades de apropriação de ideários internacionais. Revisando terminologias e conceitos. Arquitextos, ano 17, n. 203.01, 2017. Disponível em http://www.vitruvius.c om.br/revistas/read/arquitext os/17.203/6516. Acesso em: 14 ago. 2017.

BONFATO, A. C. Macedo Vieira: ressonâncias do modelo cidade-jardim. São Paulo: Senac, 2008.

BRAGA, A. M. C. (Im)possíveis Brasílias. Os projetos apresentados no concurso do plano piloto da nova capital federal. São Paulo: Alameda, 2011.

BRAGA, M. O Concurso de Brasília. São Paulo: Cosac Naify, 2010.

BRASIL. I Plano nacional de desenvolvimento (PND) - 1972-1974. Brasília: Presidência da República, 1971.

CALABI, D. História do urbanismo europeu: questões, instrumentos, casos exemplares. São Paulo: Perspectiva, 2012.

CAMARGO, J. G. da C. Urbanismo rural. Brasília: Ministério da Agricultura/INCRA, 1973.

CAMARGO, J. G. da C. Urbanismo rural para fixação condigna do homem nas áreas agrícolas.

Revista do Clube de Engenharia, v. 16, n. 324-328, p. 274-277 e 299, 1963.

CARDOSO, F. H. e MÜLLER, G. Amazônia: expansão do capitalismo. Rio de Janeiro: Centro Edelstein de Pesquisas Sociais, 2008.

CAVALCANTI, L. Le Corbusier, o Estado Novo e a formação da arquitetura moderna brasileira. In: GUERRA, A. (org.). Textos fundamentais da história da arquitetura moderna brasileira. V. 1. São Paulo: Romano Guerra, 2010. p. 109-115.

COLONIZADORA SINOP. Projeto aprovado pelo INCRA e SUDAM, c.1972.

COMPANHIA Melhoramentos Norte do Paraná. Colonização e desenvolvimento do norte do Paraná. S.I.: CMNP, 1975.

DEL PRIORE, M. e VENANCIO, R. Uma breve história do Brasil. São Paulo: Planeta, 2010. 
DEL RIO, V. Historical background. In: DEL RIO, V. e SIEMBIEDA, E. (eds.). Contemporary urbanism in Brazil: beyond Brasília. Gainesville: University Press of Florida, 2009. p. 1-36.

DERNTL, M. F. Além do plano: a construção das cidades satélites e a dinâmica centro-periferia em Brasília. In: Anais do XIV Seminário de História da Cidade e do Urbanismo. São Carlos: USP, 2016. Disponível em http://www.iau.usp.br/shcu2016/anais/wp-content/uploads/pdfs/37.pdf. Acesso em: 23 set. 2016.

GOLD, J. R. Modernity and utopia. In: HUBBARD, T. H. e SHORT, J. R. (eds.). The Sage companion to the city. Londres: Sage, 2008. P. 67-86.

GOMES, A. de C. (org.). Olhando para dentro: 1930-1964. Rio de Janeiro: Objetiva, 2013.

GORELIK, A. Das vanguardas a Brasília. Cultura urbana e arquitetura na América Latina. Belo Horizonte: Editora UFMG, 2005.

HEALEY, P. e UPTON, R. Crossing borders: International exchange and planning practices. Londres: Nova York: Routledge, 2010.

HEIN, C. Crossing boundaries: the global exchange of planning ideas. In: SANDOVAL-STRAUSZ, A. K. e KWAK, N. H. (eds.). Making cities global. The transnational turn in urban history. Filadélfia: University of Pennsylvania Press, 2017. p. 114-129.

HOLSTON, J. The modernist city. An anthropological critique of Brasilia. Chicago: The University of Chicago Press, 1989.

HOME, R. Global systems foundations of the discipline. In: HEIN, C. (ed.). The Routledge handbook of planning history. Nova York: Routledge, 2018. p. 91-106.

HOWARD, E. Garden cities of to-morrow. Cambridge, Mass.: The MIT Press, 1965.

KATZMAN, M. T. Cities and frontiers in Brazil: regional dimensions of economic development. Cambridge, Mass.: Harvard University Press, 1977.

KOOLHAAS, R. Delirious New York. Nova York: The Monacelli Press, 1994.

LEFEBVRE, H. Notes on the new town. In: DURING, S. (ed.). The cultural studies reader. Londres: Nova York: Routledge, 2007. p. 147-155.

LEME, M. C. da S. A circulação de ideias e modelos na formação do urbanismo em São Paulo, nas primeiras décadas do século XX. In: Anais do VIII Seminário de História da Cidade do Urbanismo. Niterói: UFF, $2004 . \quad$ Disponível em: http://unuhospedagem.com.br/revista/rbeur/index.php/shcu/article/viewFile/946/921. Acesso em: 18 out. 2016.

LEME, M. C. da S. (org.). Urbanismo no Brasil 1895-1965. 2 ed. Salvador: UFBA, 2005.

MANSO, C. F. A. Goiânia: uma concepção urbana, moderna e contemporânea - um certo olhar. Goiânia: Edição do autor, 2001.

MARTINS, C. A. F. Identidade nacional e Estado no projeto modernista. Modernidade, Estado e tradição. In: GUERRA, A. Textos fundamentais sobre história da arquitetura moderna brasileira. V. 1. São Paulo: Romano Guerra, 2010. P. 279-297.

MONBEIG, P. Pioneiros e Fazendeiros de São Paulo. São Paulo: Hucitec, 1984.

MORAES, A. C. R. Território e história no Brasil. São Paulo: Annablume, 2008. 
MUMFORD, E. The CIAM discourse on urbanism: 1928-1960. Cambridge, Mass.: The MIT Press, 2000.

OLDONI, S. M. Cidades novas no oeste do Paraná: os traçados criados pela colonizadora Maripá. (Dissertação de mestrado). Universidade Estadual de Maringá, Maringá, 2016.

PINHEIRO, E. P. As ideias estrangeiras criando cidades desejáveis na América do Sul: do academicismo ao modernismo. In: Actas del XI Coloquio Internacional de Geocrítica. Buenos Aires, 2010. Disponível em: http://www.ub.edu/geocrit/sn/sn-331/sn-331-11.htm. Acesso em: 28 dez. 2016.

PINHEIRO, E. P. Circulação de ideias e academicismo: os projetos urbanos para as capitais do Cone Sul, entre 1920 e 1940. In: GOMES, M. A. de F. (org.). Urbanismo na América do Sul. Salvador: EDUFBA, 2009. p. 119-148.

REGO, R. L. Palmas, the last capital city planned in twentieth-century Brazil. URBE, v. 12, e20190168, 2020. https://doi.org/10.1590/2175-3369.012.e20190168.

REGO, R. L. Ideias para novas cidades. Arquitetura e urbanismo no interior do Brasil do século XX. Londrina: Kan, 2019.

REGO, R. L. Shaping an urban Amazonia: "a planner's nightmare". Planning Perspectives, v. 32, n. 2, p. 249-270, 2017a. DOI: 10.1080/02665433.2016.1277952.

REGO, R. L. Unidade de vizinhança: um estudo de caso das transformações de uma ideia urbanística. URBE, v. 9, n. 3, p. 401-413, 2017b. DOI: 10.1590/2175-3369.009.003.AO01.

REGO, R. L. A integração cidade-campo como esquema de colonização e criação de cidades novas: do norte paranaense à Amazônia Legal. Revista Brasileira de Estudos Urbanos e Regionais, v. 17, n. 1, p. 89-103, 2015. DOI: http://dx.doi.org/10.22296/2317-1529.2015v17n1p89.

REGO, R. L. Ideias viajantes: o centro cívico e a cidade como obra de arte - do City Beautiful ao coração de Maringá. In: FREISTAS, J. F. B. e MENDONÇA, E. M. (orgs.). A construção da cidade e do urbanismo: ideias têm lugar? Vitória: EDUFES, 2012. p. 161-175.

REGO, R. L. A tropical enterprise: British planning ideas in a private settlement in Brazil. Planning Perspectives, v. 26, n. 2, p. 261-282, 2011. DOI: 10.1080/02665433.2011.550448.

REIS, P. O. B. Palmas: um projeto de múltiplos olhares. Palmas: EDUFT, 2015.

REZENDE, V. (org.). Urbanismo na era Vargas: a transformação das cidades brasileiras. Niterói: UFF, 2012.

RICARDO, C. Marcha para oeste. A influência da "bandeira" na formação social do Brasil. Rio de Janeiro: José Olympio, 1959.

RIGOTTI, A. M. Le Corbusier's plan for Buenos Aires. Useful explanations on the birth of the cities. Journal of Architecture and Urbanism, v. 40, n. 2, 121-130, 2016. DOI: 10.3846/20297955.2016.1189366.

ROMERO, J. L. América Latina. As cidades e as ideias. Rio de Janeiro: Editora UFRJ, 2009.

ROSANELLI, A. Grid plan new towns in the brazilian coffee frontier. Journal of Urban Design, v. 19, n. 5, p. 638-659, 2014.

ROWE, C. The architecture of utopia. In: ROWE, C. The mathematics of the ideal villa and other essays. Cambridge, Mass.: The MIT Press, 1976. p. 205-223. 
SAID, E. W. Traveling theory. In: SAID, E. W. The world, the text, and the critic. Cambridge: Harvard University Press, 1983. p. 157-181.

SEGAWA, H. Arquiteturas no Brasil 1900-1990. São Paulo: EDUSP, 1997.

SUTCLIFFE, A. Towards the planned city. Germany, Britain, the United States and France, 17801914. Oxford: Basil Blackwell, 1981.

TAVARES, J. Projetos para Brasília, 1927-1957. Brasília: IPHAN, 2014.

TOTA, A. P. O imperialismo sedutor. A americanização do Brasil na época da Segunda Guerra. São Paulo: Companhia das Letras, 2000.

TREVISAN, R. Cidades Novas. (Tese de doutorado). Universidade de Brasília, Brasília, 2009.

TREVISAN, R., FICHER, S. e MATTOS, F. M. Brasil: um século, cinco cidades novas administrativas. In: Anais do XVII ENANPUR. São Paulo: FAUUSP, 2017. Disponível em http://anpur.org.br/xviienanpur/principal/publicacoes/XVII.ENANPUR_Anais/XVII.ENANPUR_Indice_Se ssoes_Livres_e_Tematicas.pdf. Acesso em: 25 jun. 2020.

VIDAL, L. De Nova Lisboa a Brasília: a invenção de uma capital (séculos XIX-XX). Brasília: UnB, 2009.

VOCABULAIRE illustré de l'art urbain. Lyon: Éditions du Certu, 2010. Disponível em <https://www.arturbain.fr/arturbain/vocabulaire/francais/. Acesso em: 22 jul. 2020.

WAIBEL, L. H. As zonas pioneiras do Brasil. Revista Brasileira de Geografia, ano XVII, n. 4, p. 389422, 1955.

WAKEMAN, R. Practicing utopia. An intellectual history of the new town movement. Chicago: Londres: The University of Chicago Press, 2016.

WARD, S. V. Planning diffusion. Agents, mechanisms, networks, and theories. In: HEIN, C. (ed.). The Routledge handbook of planning history. Nova York: Routledge, 2018. p. 76-90.

WARD, S. V. Transnational planners in a postcolonial world. In: HEALEY, P. e UPTON, R. (ed.). Crossing borders. International exchange and planning practices. Londres: Nova York: Routledge, 2010. P. 47-72.

WARD, S. V. Re-examining the international diffusion of planning. In: FREESTONE, R. (ed.). Urban planning in a changing world: the twentieth century experience. Londres: E \& FN Spon, 2000. P. 4060.

WARD, S. V. (ed.). The Garden City. Past, Present and Future. Londres: E \& FN Spon, 1992.

WILHEIM, J. A obra pública de Jorge Wilheim. São Paulo: Dorea Books, 2003.

XAVIER, A. e KATINSKY, J. (orgs.). Brasília: antologia crítica. São Paulo: Cosac Naify, 2012. 